\title{
Cu(0)-RDRP of Methacrylates in DMSO: Importance of the initiator
}

\author{
Glen R. Jones, ${ }^{1 \dagger}$ Richard Whitfield, ${ }^{1 \dagger}$ Athina Anastasaki, ${ }^{1,2}$ Nuttapol Risangud, \\ Alexandre Simula, ${ }^{3}$ Daniel J. Keddie, ${ }^{4}$ David M. Haddleton*1 \\ ${ }^{1}$ University of Warwick, Department of Chemistry, Library Road, Coventry, CV4 7AL, UK. \\ 2 Materials Research Laboratory, University of California, Santa Barbara, California, 93106, \\ USA. \\ ${ }^{3}$ POLYMAT and Kimika Aplikatua Saila, University of the Basque Country UPV/EHU, \\ Joxe Mari Korta Zentroa, Tolosa Hiribidea 72, 20018, Donostia/San Sebastián, Spain. \\ ${ }^{4}$ University of Wolverhampton, School of Biology, Chemistry and Forensic Science, \\ Wulfruna Street, Wolverhampton, WV1, 1SE, UK. \\ ${ }^{\dagger}$ Both authors contributed equally to this work \\ Correspondence to: David M. Haddleton (E-mail: d.m.haddleton@warwick.ac.uk)
}

\begin{abstract}
The controlled radical polymerization of methacrylates via $\mathrm{Cu}(0)$-mediated $\mathrm{RDRP}$ is challenging in comparison to acrylates with most reports illustrating higher dispersities, lower monomer conversions and poorer end group fidelity relative to the acrylic analogues. Herein, we present the successful synthesis of poly(methyl methacrylate) (PMMA) in DMSO by judicious selection of optimal reaction conditions. The effect of the initiator, ligand and temperature on the rate and control of the polymerization is investigated and discussed. Under carefully optimized conditions enhanced control over the molecular weight distributions is obtained furnishing methacrylic polymers with dispersities as low as 1.10, even at very high conversions. A range of methacrylates were found to be tolerant to the optimized polymerization conditions including hydrophobic, hydrophilic and functional methacrylates including methyl and benzyl methacrylate, ethylene glycol methyl ether methacrylate and glycidyl methacrylate. The control retained during the polymerization is further highlighted by in situ chain extensions yielding well-defined block polymethacrylates.
\end{abstract}




\section{Introduction}

$\mathrm{Cu}(0)$-mediated reversible deactivation radical polymerization (RDRP) has emerged as a useful and versatile tool for the synthesis of polymers in both aqueous and organic media, yielding very well-defined materials often with complex and designed macromolecular architectures. ${ }^{1-9}$ When compared to other controlled/living radical polymerizations methods, $\mathrm{Cu}(0)$-mediated RDRP exhibits a number of advantages including narrow molecular weight distributions, or dispersity, even at near quantitative conversions, high end group functionality, very low concentrations of copper ( $\mathrm{ppm}$ ) with both a simple set up and deoxygenation procedures. ${ }^{10,11}$ Importantly, the majority of the polymerizations are performed at ambient temperature or below thus allowing additional access to well defined protein/polymer conjugates and monomers that exhibit an LCST behaviour upon polymerization. $^{12-16}$

Acrylates and acrylamides are the most studied monomer classes investigated by $\mathrm{Cu}(0)$ mediated RDRP, with methyl acrylate (MA) and $N$-isopropylacrylamide (NIPAM) often used as model monomers for the optimization of reaction conditions. $\mathrm{Cu}(0)$-wire and $\mathrm{Cu}(0)$ particles, either externally added or generated in situ via disproportionation of $\mathrm{CuBr} / \mathrm{Me}_{6} \mathrm{Tren}$ (tris[2-(dimethylamino)ethyl]amine) systems have been extensively explored to afford the polymerization of a wide range of hydrophobic, hydrophilic, semi-fluorinated and functional acrylates and acrylamides to yield polymers with narrow molecular weight distributions. ${ }^{12,17-}$ ${ }^{19}$ A number of complex architectures further demonstrates the good control and high end group fidelity accessible through these techniques as shown by the synthesis of sequence controlled multiblock copolymers, ${ }^{20,21}$ stars $^{22-25}$ and dendritic hyperbranched structures. ${ }^{26}$

In contrast to acrylates and acrylamides, reports of the RDRP of methacrylates using $\mathrm{Cu}(0)-$ based synthetic protocols are far fewer in number. Both Percec and Perrier have reported the controlled polymerization of methacrylates via $\mathrm{Cu}(0)$-RDRP with initiators such as aryl sulfonyl halides and ethyl bromoisobutyrate $(\mathrm{EBiB})$, although the resultant materials exhibit moderate control over the molecular weight distributions (Đ typically $>1.20-1.30$ ) when compared to the acrylic analogues $(Đ$ typically $\sim 1.10){ }^{1,2,8,27-30}$ The synthesis of in situ block copolymers was not reported in these syntheses. Conversions of 50-80\% are typically reported and the monomers exemplified are usually limited to MMA; monomers with higher degrees of functionality have yet to be exploited in this context. Furthermore, relatively high 
temperatures $\left(>60^{\circ} \mathrm{C}\right)$ are often required for these polymerizations, thus limiting the application of the yielding polymers.

Herein, we demonstrate how to circumvent these challenges by investigating the effect of the initiator, temperature and ligand so as to identify optimal polymerization conditions specifically for methacrylates as opposed to universal conditions that work for all monomer types albeit with certain compromises in each case. ${ }^{31}$ Methyl $\alpha$-bromophenylacetate (MBPA) is an active and commercially available initiator and facilitates the controlled polymerization of MMA and a range of hydrophobic, hydrophilic and functional methacrylates at ambient temperature. The preparation of polymers of low dispersity at high monomer conversion, (>90\%), access to high molar molecular weight polymers (>70 kDa) and successful synthesis of block copolymers via in situ block extension highlight the utility of the optimized conditions.

\section{Experimental}

\section{Materials and Instrumentation}

Ethyl 2-bromopropionate (EBP), ethyl $\alpha$-bromoisobutyrate (EBiB), methyl $\alpha$-bromophenyl acetate (MBPA) and all other materials were purchased from Sigma Aldrich and used as received unless otherwise stated. Tris[2-(dimethylamino)ethyl]-amine ( $\mathrm{Me}_{6}$ Tren) was synthesized according to literature procedure and stored under nitrogen and refrigerated prior to use. ${ }^{32} \mathrm{Cu}(0)$ (gauge $0.25 \mathrm{~mm}$ ) wire was purchased from Comax Engineered wires and was treated by immersion in aq. $37 \% \mathrm{w} / \mathrm{v} \mathrm{HCl}$ prior to use. ${ }^{1} \mathrm{H}$ NMR spectra were recorded on Bruker AV-300, HD-300 and HD-400 MHz spectrometers at $25{ }^{\circ} \mathrm{C}$ using deuterated chloroform as the solvent. SEC was performed using an Agilent 390-LC MDS instrument was equipped with differential refractive index (DRI) and dual wavelength UV detectors. The system was equipped with 2 x PLgel Mixed C columns $(300 \times 7.5 \mathrm{~mm})$ and a PLgel $5 \mu \mathrm{m}$ guard column. The eluent was either THF with $2 \% \mathrm{w} / \mathrm{v}$ TEA (triethylamine) or $0.01 \% \mathrm{w} / \mathrm{v}$ BHT (butylated hydroxytoluene) additives run at $1 \mathrm{~mL} / \mathrm{min}$ at $30{ }^{\circ} \mathrm{C}$ or DMF with $5 \mathrm{mmol}$ $\mathrm{NH}_{4} \mathrm{BF}_{4}$ additive run at $1 \mathrm{~mL} / \mathrm{min}$ at $50{ }^{\circ} \mathrm{C}$. Poly(methyl methacrylate) (Agilent Polymethyl Methacrylate EasiVials between 550 and 1.5 million $\mathrm{g} \mathrm{mol}^{-1}$ ) and polystyrene standards (Agilent Polystyrene Medium EasiVials between 162 and 364,000 $\mathrm{g} \mathrm{mol}^{-1}$ ) were used for calibration and fitted with a second order polynomial. Analyte samples were filtered through a GVHP membrane with $0.22 \mu \mathrm{m}$ pore size before injection. Respectively, experimental 
molar mass $\left(\mathrm{M}_{n}\right.$ SEC) and dispersity $(\nexists)$ values of synthesized polymers were determined by conventional calibration using Agilent SEC software.

Typical $\mathrm{Cu}(0)$ mediated polymerization of MMA in DMSO: $\mathrm{Cu}(\mathrm{II}) \mathrm{Br}_{2}(8.4 \mathrm{mg}, 0.037 \mathrm{mmol}$, 0.05 eq.) was charged to a $25 \mathrm{~mL}$ glass vial and dissolved in $4 \mathrm{~mL}$ of DMSO. MMA (4 mL, $37.4 \mathrm{mmol}, 50$ eq.) was added and MBPA (118 $\mu \mathrm{L}, 0.75 \mathrm{mmol}, 1$ eq.) was carefully transferred into the reaction vessel via microliter syringe. Concurrently, in a separate vial, a stirrer bar wrapped with $5 \mathrm{~cm}$ of copper wire was immersed in $37 \% \mathrm{HCl}$, stirred for 15 minutes, washed sequentially with water and acetone, and dried. The stirrer bar was then placed into the reaction vessel, sealed with a rubber septum, and degoxygenated by bubbling with nitrogen for 15 minutes in an oil bath at $25{ }^{\circ} \mathrm{C}$. After this time a degassed aliquot of $\mathrm{Me}_{6}$ Tren (36 $\mu \mathrm{L}, 0.13 \mathrm{mmol}, 0.18$ eq.) was injected into the vial via microliter syringe. The reaction was left to proceed overnight and samples were taken and analyzed via ${ }^{1} \mathrm{H}$ NMR and SEC.

Example of $\mathrm{Cu}(0)$ mediated polymerization of $M M A$ in DMSO with online FT-NIR monitoring: $\mathrm{Cu}(\mathrm{II}) \mathrm{Br}_{2}(16 \mathrm{mg}, 71 \mu \mathrm{mol}, 0.05$ eq. $)$ was charged to a $25 \mathrm{~mL}$ Schlenk tube and dissolved in $7.5 \mathrm{~mL}$ of DMSO. MMA (7.5 mL, $71 \mathrm{mmol}, 50$ eq.) was added and Me6Tren (68 $\mu \mathrm{L}, 0.25 \mathrm{mmol}, 0.18$ eq.) was added via microliter syringe. Finally, MBPA (223 $\mu \mathrm{L}, 1.41$ mmol, 1 eq.) was added. Concurrently, in a separate vial, a stirrer bar wrapped with $10 \mathrm{~cm}$ of copper wire was immersed in $37 \% \mathrm{HCl}$, stirred for 15 minutes, washed sequentially with water and acetone, and dried. The stirrer bar was then placed in the Schlenk tube, suspended above the reaction mixture using a magnet. The Schlenk tube was sealed using a ground glass stopper fitted with a septum through which the fibre optic FT-NIR probe was fitted. The reaction mixture was then degassed by three freeze-pump-thaw cycles, placed into an oil bath at $25{ }^{\circ} \mathrm{C}$ and the magnet removed, resulting in the stirrer bar dropping into the monomer/DMSO mixture and the reaction starting. Online monitoring of polymerizations via Fourier transform near-infrared (FT-NIR) spectroscopy was conducted on a Bruker vector22/N-F machine equipped with a HELLMA fibre-optic probe $(3 \mathrm{~mm})$ with 64 scans performed sequentially every 30 minutes between 6000 and 6300 wavenumbers. Conversions were calculated via integration of the $\gamma\left(=\mathrm{CH}_{2}\right)$ absorption peak $\left(6170 \mathrm{~cm}^{-1}\right)$, in comparison to the integration at time zero.

\section{Results and Discussion}


$\mathrm{Cu}(0)$-wire mediated polymerization of acrylates is often conducted at ambient temperature using $\mathrm{Me}_{6}$ Tren as the ligand, $\mathrm{EBiB}$ as a typical initiator, DMSO as the solvent with a small amount of $\mathrm{CuBr}_{2}$ added to deactivate the polymer chains so to yield narrower molecular weight distributions. Under these conditions, low dispersity and high end group fidelity poly(methyl acrylate), capable of facilitating in-situ chain extensions) can be observed at high monomer conversion, consistent with previous reports (Table 1, Figure S1-2, SI). ${ }^{10,11,33}$ The use of DMSO, a disproportionating solvent which solubilizes $\mathrm{Cu}(\mathrm{II})$, has previously been shown to furnish polymers with high end group fidelity. ${ }^{34-36}$ On switching from the tertiary initiator $(\mathrm{EBiB})$ to the secondary (EBP), MA exhibited comparable polymerization rate, polymer dispersity and end group fidelity with good agreement between theoretical and experimental molecular weights (Entries 1-2, table 1). In stark contrast, the polymerization of MA initiated with MBPA exhibited substantially lower monomer conversion even after a significantly longer reaction time $(24 \mathrm{~h})$ (Entry 3, Table 1). This is ascribed to an lower rate of initiation $\left(\mathrm{k}_{i}\right)$ from the highly-stabilized MBPA-derived radical towards MA to give a substantially less stabilized PMA propagating radical (i.e. $\mathrm{k}_{\text {act,MBPA }} \gg \mathrm{k}_{\mathrm{i}}$ and $\mathrm{k}_{\mathrm{act}, \mathrm{MBPA}}>\mathrm{k}_{\mathrm{act}}$, PMA). Although low dispersity was observed in this case, the slow rate of polymerization manifests in the inability to reach high conversion even after a prolonged reaction time. This led us to conclude that MBPA is not the optimal initiator to facilitate the controlled polymerization of acrylates under these conditions employed.

Table 1. Polymerization of MA and MMA with different initiators (SEC data for entries 4-6 shown in figure 1.)

\begin{tabular}{rccccccc}
\hline Entry & Monomer & Initiator & $\begin{array}{c}\text { Time } \\
\text { (h) }\end{array}$ & $\begin{array}{c}\text { Conversion } \\
\text { (\%) }\end{array}$ & $\begin{array}{c}\mathbf{M}_{\boldsymbol{n} \text { (Theo.) }} \\
\text { (Da) }\end{array}$ & $\mathbf{M}_{\boldsymbol{n}, \text { (SEC) }}$ & $\boldsymbol{\Xi}$ \\
& & & & & & \\
\hline 1 & \multirow{2}{*}{ Methyl } & EBP & 3 & 98 & 4400 & 4200 & 1.06 \\
2 & Acrylate & EBiB & 3 & 97 & 4300 & 4600 & 1.10 \\
3 & & MBPA & 24 & 55 & 3000 & 4900 & 1.09 \\
\hline 4 & \multirow{2}{*}{ MMA } & EBP & 24 & 38 & 2000 & 6500 & 2.12 \\
5 & & EBiB & 24 & 80 & 4100 & 7200 & 1.49 \\
6 & & MBPA & 24 & 90 & 5000 & 8200 & 1.10
\end{tabular}



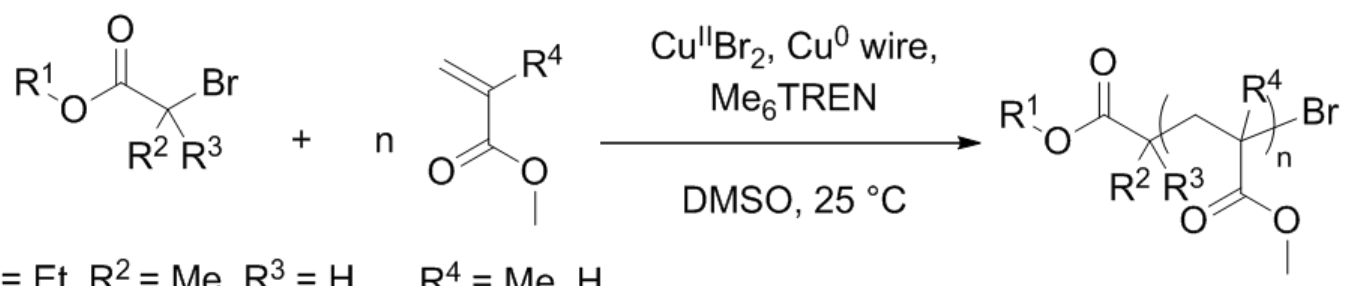
(a) $\mathrm{R}^{1}=\mathrm{Et}, \mathrm{R}^{2}=\mathrm{Me}, \mathrm{R}^{3}=\mathrm{H} \quad \mathrm{R}^{4}=\mathrm{Me}, \mathrm{H}$
(b) $R^{1}=E t, R^{2}=R^{3}=M e$
(c) $\mathrm{R}^{1}=\mathrm{Me}, \mathrm{R}^{2}=\mathrm{Ph}, \mathrm{R}^{3}=\mathrm{H}$

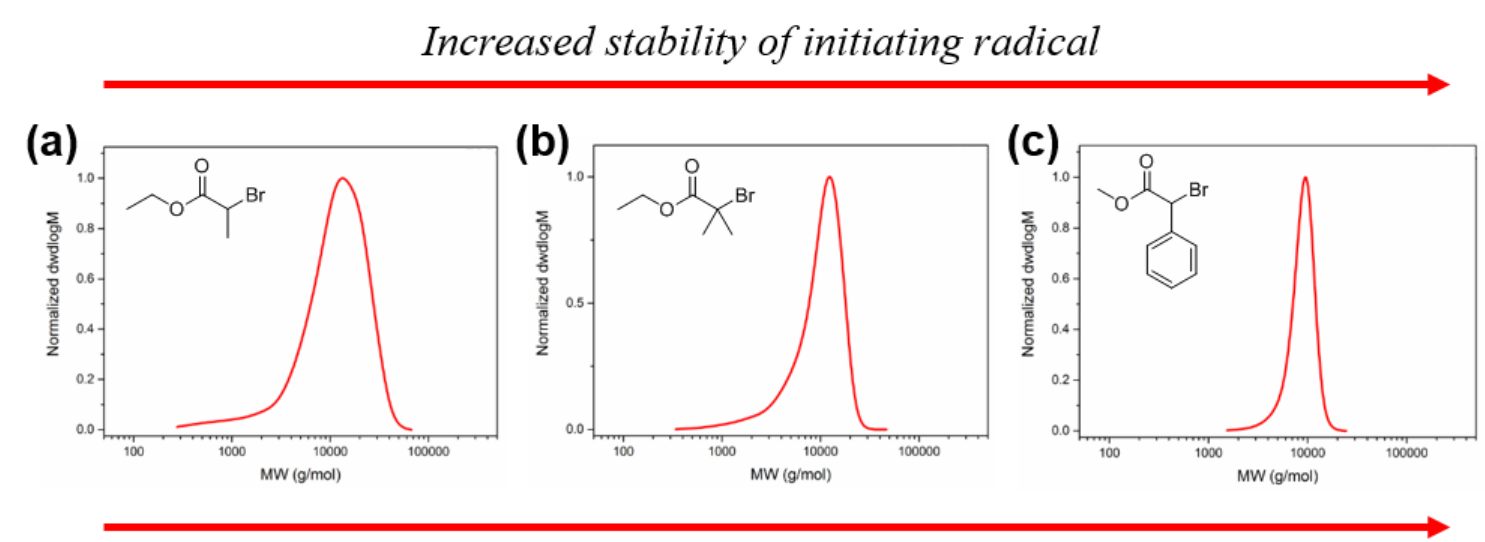

Increased control of polymerization

Figure 1. Top: Scheme showing $\mathrm{Cu}(0)-\mathrm{RDRP}$ of MMA with different initiators. Bottom: Illustration of narrowing of molecular weight distribution as the stability of the initiating radical is increased; (a) EBP, (b) EBiB, (c) MBPA (data from table 1).

Under identical reaction conditions neither $\mathrm{EBiB}$ nor $\mathrm{EBP}$ were able to provide a high degree of control over the polymerization of MMA, yielding polymers with relatively high dispersity (Entries 4-5, Table 1, Figure 1a, b) and in the case of EBP, limited conversion (38\%, entry 4, table 1). However, when the same conditions were employed using MBPA as the initiating species PMMA could be synthesized with a dispersity $=1.10$ even at high conversion $(90 \%$, entry 6, table 1, Figure 1c). As expected in comparison to the MA examples, the polymerization of MMA was much slower due to the lower propagation rate constant $\left(\mathrm{k}_{\mathrm{p}}\right)$ for MMA polymerization. ${ }^{37}$ Discrepancies between theoretical and observed $\mathbf{M}_{n}$ for the polymerization of MMA are attributed to reduced initiator efficiency (75\%) as previously reported. ${ }^{30,38,39}$ It is noted that initiator efficiency was found to be slightly improved upon addition of higher amounts of $\mathrm{Cu}(\mathrm{II}) \mathrm{Br}_{2}$ (figure S5, SI) although upon increasing the ligand concentration control of the polymerization was lost, consistent with previous literature 
reports. ${ }^{40}$ In addition to this it also reported that addition of $5 \%$ of $\mathrm{Cu}(\mathrm{II}) \mathrm{Br}_{2}$ is beneficial as it allows for more efficient synthesis of diblock copolymers via in-situ approaches. ${ }^{41}$

Polymerization of MMA under the optimized conditions was repeated at three different temperatures, in order to ascertain whether increased temperature could yield greater polymerization rates and higher conversions whilst maintaining the good degree of control over MWDs. At $50^{\circ} \mathrm{C}$ it was found that the reaction proceeds much faster, with conversion = $65 \%$ by ${ }^{1} \mathrm{H}$ NMR after three hours, compared to just $5 \%$ at $25{ }^{\circ} \mathrm{C}$. However, after 24 hours the reaction had only reached a marginally higher conversion (94\% compared to $90 \%$ at 25 $\left.{ }^{\circ} \mathrm{C}\right)$, and furthermore the dispersity was significantly broader $\left(\nexists=1.30\right.$ at $50{ }^{\circ} \mathrm{C}$, compared to 1.10 at $25^{\circ} \mathrm{C}$ ). At $75^{\circ} \mathrm{C}$, this trend is further illustrated with conversion reaching almost $90 \%$ in 3 hours, but an even broader dispersity. All subsequent reactions were performed at ambient temperature to minimize the termination events occurring at higher temperatures. Previous studies investigating the $\mathrm{Cu}(0)$ mediated polymerization of methacrylate monomers have highlighted the choice of ligand as an important parameter for achieving a desired controlled process. With this in mind polymerizations of MMA with the three initiators described previously were repeated using PMDETA, a ligand previously reported as successful for the polymerization of MMA, ${ }^{31,42}$ as the ligand (table S4, SI), however, a significant increase in dispersity of resultant polymers was noted (figures S8-10, SI) highlighting significant variations between different copper mediated protocols.

In order to gain a better understanding of these polymerizations, kinetic analysis using online FT-NIR monitoring was employed allowing for the measurement of monomer conversion as a function of time (Figure S4, SI). The FT-NIR spectrum of MMA reveals a prominent signal at $6170 \mathrm{~cm}^{-1}$ (from the first overtone of the $2 \gamma\left(=\mathrm{CH}_{2}\right)$ absorption) which upon integration allows for the relative monomer concentration to be calculated, as previously reported by Haddleton et. al. ${ }^{43,44}$ The first order kinetic plot $\left(\ln \left[\mathrm{M}_{0}\right] /\left[\mathrm{M}_{\mathrm{t}}\right]\right.$ vs time) for the polymerization of MMA was obtained by measuring the relative decrease in the absorption at $6170 \mathrm{~cm}^{-1}$ (ascribed to the vinyl group of the monomer) as the monomer is converted to polymer. Figure 2a shows the kinetic plot for the polymerization of MMA with EBP (an initiator which forms a secondary radical), it can be seen that there is no linear relationship, indicating a nonconstant concentration of radicals which results in an uncontrolled reaction (final dispersity = 2.12) (Figures 1a, 2a). When EBiB was employed (an initiator capable of generating a more stable tertiary radical) linear kinetics were only observed up to $4 \mathrm{~h}$, before a subsequent loss of linearity and loss of control (figure 2b). The lack of control of this polymerization is 
highlighted by SEC analysis of the final sample which exhibited a dispersity of 1.60 (Figure 1b). On the contrary kinetic analysis of the polymerization using MBPA, an initiator where the initiating radical is further resonance stabilized by the adjacent phenyl group, a much more linear behaviour was observed following an initial induction period (attributed to selective initiation, where MPBA is transformed to the single monomer unit adduct prior to polymerization of MMA) that has also been previously observed (Figure 2c). ${ }^{45,} 46$ Importantly, the final sample exhibited a narrow molecular weight distribution $(\nexists=1.10$ at 90\% conversion), demonstrating an impressive degree of control over the polymerization (Figure 1).

(a)

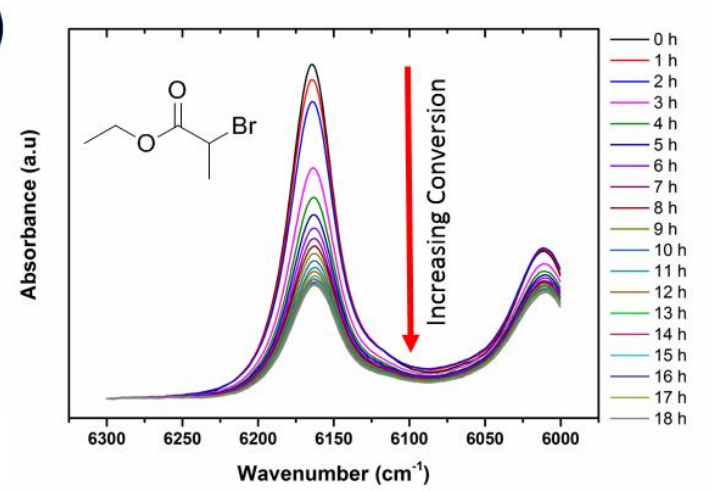

(b)

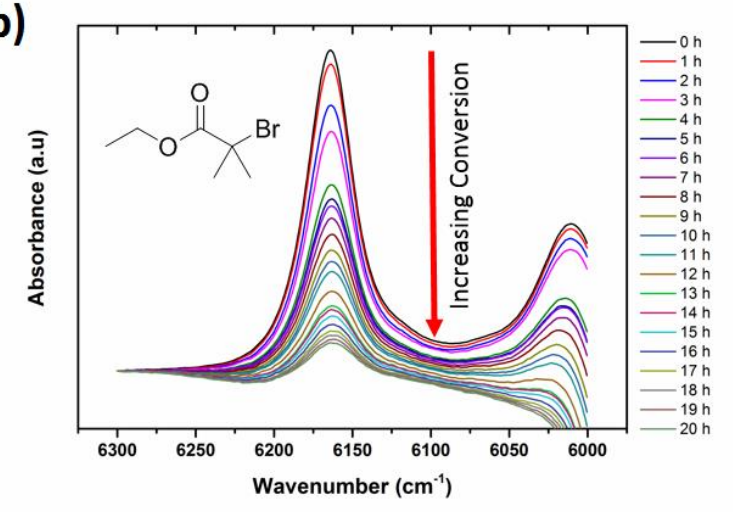

(c)

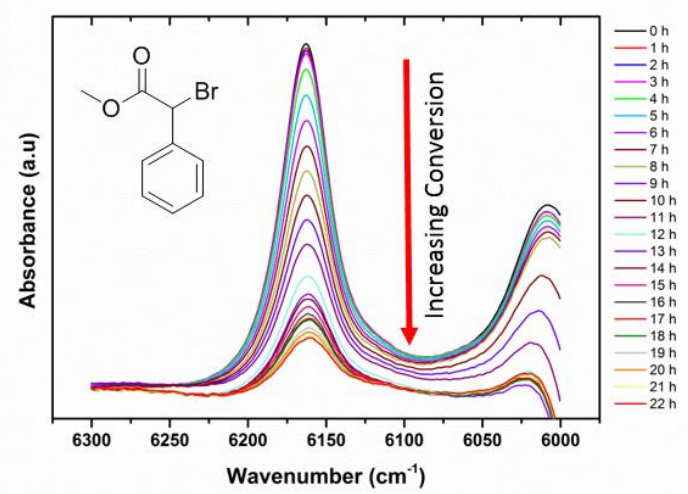

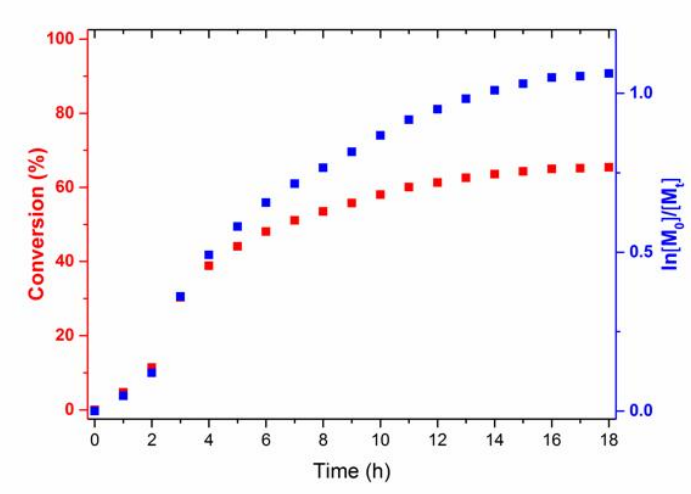
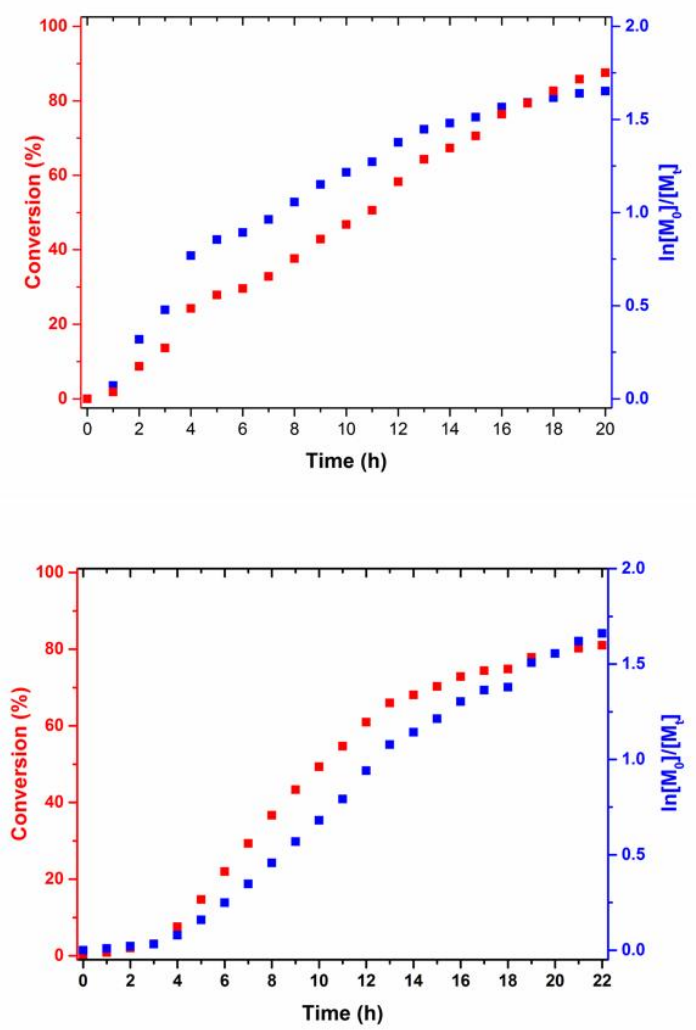
Figure 2. FT-NIR data showing a decrease in $=\mathrm{CH}_{2}$ absorption over time for the polymerization of MMA with (a) EBP, (b) EBiB and (c) MBPA as initiators.

The "cross-propagation" of the more electron rich MBPA initiator derived radical to MMA is faster than the homopropagation of PMMA to MMA and the MPBA derived radical is more stable as it is doubly stabilized by two resonance stabilizing groups; $\mathrm{PMMA}^{*}$ is less stable (one resonance stabilizing group.) This results in initiation being a much faster process that propagation, so all polymer chains have an equal chance of propagating and are therefore similar in length (hence a narrow molecular weight distribution is obtained.) In the case of $\mathrm{EBP}$ and $\mathrm{EBiB}$ the $\mathrm{PMMA}^{\circ}$ is more stable due to the back strain effect, in which the release of steric strain from the dormant PMMA-Br species as it undergoes transformation from a $\mathrm{sp}^{3}$ hybridized to $\mathrm{sp}^{2}$ hybridized configuration through activation makes the formation of the radical more enthalpically valuable. ${ }^{47,48}$ Taken altogether, this data concludes that in the case of acrylates, all three initiators result in narrow molecular weight distributions although clearly MBPA is less ideal due to much slower polymerization rates. On the contrary, in the case of methacrylates only MBPA can facilitate a well-controlled polymerization delivering polymers of low dispersity.

To probe the potential of these optimized conditions to deliver polymers with narrow MWDs for higher MW polymers, a series of PMMAs were synthesized targeting higher degrees of polymerization $\left(\left(\mathrm{DP}_{n}=100-400\right)\right.$, Table 2$)$. In all cases these experiments yielded polymers with low dispersity (1.10-1.24) up to $73000 \mathrm{~g} \mathrm{~mol}^{-1}$ (Figure 3a). Furthermore, in situ chain extension of PMMA with a second aliquot of MMA led to a complete shift of the molecular weight distribution while maintaining low dispersity indicating high end group fidelity even at high monomer conversion (Figure S12, Table S4, SI). A range of other methacrylates were also found to be compatible with these polymerization conditions including ethyl methacrylate (EMA), benzyl methacrylate (BzMA), ethylene glycol methyl ether methacrylate (EGMA), poly(ethylene glycol methyl ether methacrylate) (PEGMA) and glycidyl methacrylate (GMA) (Figures S13-17, SI). Importantly, GMA allows for further post polymerization modification ${ }^{49}$ and here monomer conversion reached $99 \%$ furnishing the desired PGMA with a final dispersity of 1.10. In order to further assess the end group fidelity at such high conversion, an aliquot of MMA was subsequently added yielding a well-defined PGMA-PMMA diblock copolymer upon polymerization with $\mathrm{M}_{n}=18400 \mathrm{~g} \mathrm{~mol}^{-1}$ and a final dispersity $=1.15$. 
Table 2. Polymerization of MMA of various molecular weights, polymerization of a range of functional methacrylate monomers under optimized conditions.

\begin{tabular}{|c|c|c|c|c|c|c|}
\hline Entry & Monomer & $\begin{array}{c}\text { Targeted } \\
\mathrm{DP}_{n}\end{array}$ & $\begin{array}{c}\text { Conversio } \\
\text { n (\%) }\end{array}$ & $\mathrm{M}_{n \text { (Theo.) }}(\mathrm{Da})$ & $\mathbf{M}_{n(S E C)}(\mathrm{Da})$ & $\boldsymbol{\theta}$ \\
\hline 1 & & 50 & 90 & 4700 & 8200 & 1.10 \\
\hline 2 & & 100 & 84 & 8600 & 15100 & 1.19 \\
\hline \multicolumn{7}{|c|}{ MMA } \\
\hline 3 & & 200 & 82 & 17000 & 32900 & 1.24 \\
\hline 4 & & 400 & 75 & 30200 & 73400 & 1.24 \\
\hline 5 & $\begin{array}{c}\text { Ethyl } \\
\text { Methacrylate }\end{array}$ & 50 & 95 & 5600 & 11700 & 1.13 \\
\hline 6 & $\begin{array}{c}\text { Benzyl } \\
\text { Methacrylate }\end{array}$ & 50 & 92 & 8300 & 10900 & 1.22 \\
\hline 7 & $\begin{array}{c}\text { Glycidyl } \\
\text { Methacrylate }\end{array}$ & 50 & $>99$ & 7300 & 8800 & 1.11 \\
\hline 8 & $\begin{array}{l}\text { Ethylene glycol } \\
\text { methyl ether } \\
\text { methacrylate }\end{array}$ & 50 & $>99$ & 7400 & 7000 & 1.18 \\
\hline 9 & $\begin{array}{l}\text { Poly(ethylene } \\
\text { glycol) methyl } \\
\text { ether } \\
\text { methacrylate }\end{array}$ & 50 & 92 & 23200 & 36300 & 1.21 \\
\hline
\end{tabular}



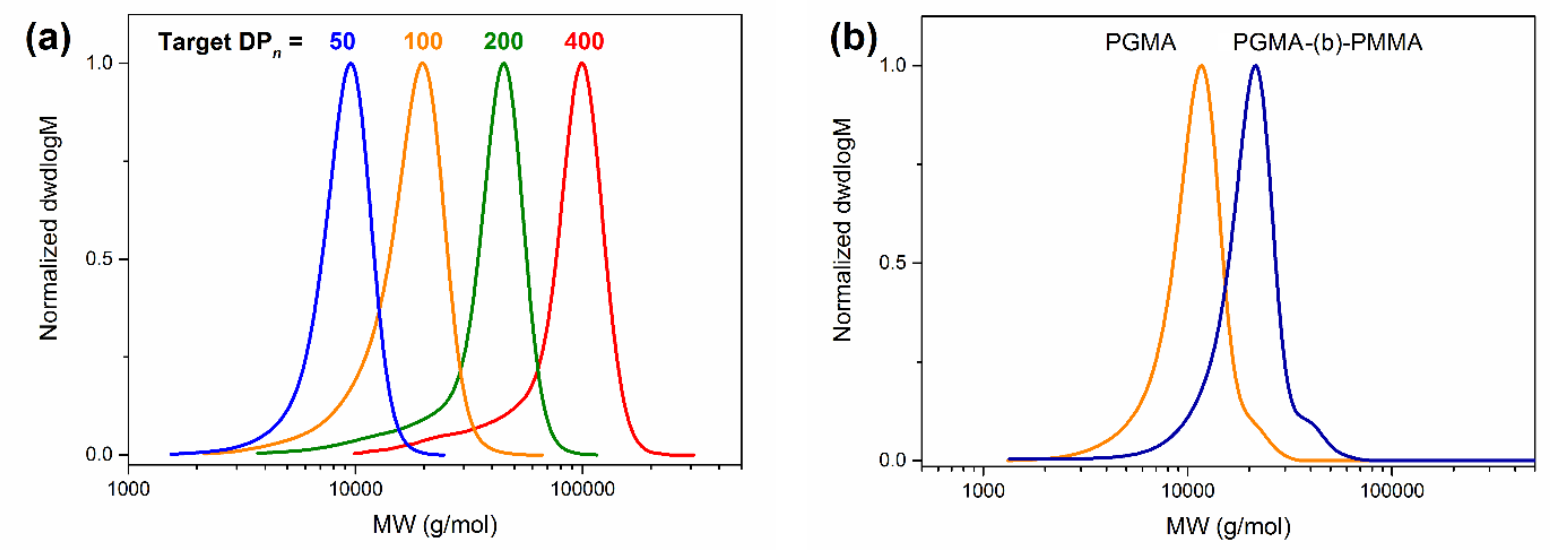

Figure 3. (a) SEC traces of PMMA with different targeted DP's (entries 1-4 table 2), (b) SEC trace of PGMA-(b)-PMMA block copolymer.

\section{Conclusions}

This work presents the a $\mathrm{Cu}(0)$ based system capable of controlled polymerization of a range of hydrophobic, hydrophilic and functional methacrylates utilizing one set of conditions. We have demonstrated that appropriate choice of initiator is a vital parameter in controlling the $\mathrm{Cu}(0)$ mediated polymerization of methacrylates, with a more active initiating species achieving a greater degree of control, as evidenced by narrow molecular weight distributions and pseudo-linear first order kinetics as observed by online monitoring with Near IR spectroscopy. Optimized conditions were also shown to be applicable to higher molecular weights and high end group fidelity could be maintained even at very high conversions (>99\%), as exemplified by the in situ chain extension of PGMA with MMA to form the desired block copolymer with low dispersity.

\section{Acknowledgements}

We appreciate financial support from the University of Warwick (G.R.J., R.W.), the Lubrizol Corporation (G.R.J.) and Syngenta (R.W.). We also thank the MRSEC and PREM programs of the National Science Foundation (DMR-1121053 and DMR-1205194) for financial support (A.A.) The MRL Central Facilities are supported by the MRSEC Program of the NSF under Award No. DMR 1121053; a member of the NSF-funded Materials Research Facilities Network (www.mrfn.org). A.A. acknowledges the Global Marie Curie Fellowship for financial support (BINAMA EC 705041). 


\section{References}

1. V. Percec, T. Guliashvili, J. S. Ladislaw, A. Wistrand, A. Stjerndahl, M. J. Sienkowska, M. J. Monteiro and S. Sahoo, J. Am. Chem. Soc., 2006, 128, 14156-14165.

2. B. M. Rosen and V. Percec, Chem. Rev., 2009, 109, 5069-5119.

3. D. Konkolewicz, Y. Wang, P. Krys, M. Zhong, A. A. Isse, A. Gennaro and K. Matyjaszewski, Polym. Chem., 2014, 5, 4396-4417.

4. D. Konkolewicz, Y. Wang, M. Zhong, P. Krys, A. A. Isse, A. Gennaro and K. Matyjaszewski, Macromolecules, 2013, 46, 8749-8772.

5. S. Harrisson, P. Couvreur and J. Nicolas, Macromolecules, 2012, 45, 7388-7396.

6. S. Harrisson and J. Nicolas, ACS Macro Lett., 2014, 3, 643-647.

7. N. Zhang, S. R. Samanta, B. M. Rosen and V. Percec, Chem. Rev., 2014, 114, 5848-5958.

8. G. Lligadas, S. Grama and V. Percec, Biomacromolecules, 2017, 18, 1039-1063.

9. V. Ladmiral, E. Melia and D. M. Haddleton, European Polymer Journal, 2004, 40, 431-449.

10. A. Anastasaki, V. Nikolaou and D. M. Haddleton, Polym. Chem., 2016, 7, 1002-1026.

11. A. Anastasaki, V. Nikolaou, G. Nurumbetov, P. Wilson, K. Kempe, J. F. Quinn, T. P. Davis, M. R. Whittaker and D. M. Haddleton, Chem. Rev., 2016, 116, 835-877.

12. Q. Zhang, P. Wilson, Z. Li, R. McHale, J. Godfrey, A. Anastasaki, C. Waldron and D. M. Haddleton, J. Am. Chem. Soc., 2013, 135, 7355-7363.

13. Q. Zhang, M. Li, C. Zhu, G. Nurumbetov, Z. Li, P. Wilson, K. Kempe and D. M. Haddleton, J. Am. Chem. Soc., 2015, 137, 9344-9353.

14. P. Wilson, A. Anastasaki, M. R. Owen, K. Kempe, D. M. Haddleton, S. K. Mann, A. P. R. Johnston, J. F. Quinn, M. R. Whittaker, P. J. Hogg and T. P. Davis, J. Am. Chem. Soc., 2015, 137, 4215-4222.

15. J. Collins, J. Tanaka, P. Wilson, K. Kempe, T. P. Davis, M. P. Mclntosh, M. R. Whittaker and D. M. Haddleton, Bioconjugate Chem., 2015, 26, 633-638.

16. C. Boyer, N. A. Corrigan, K. Jung, D. Nguyen, T.-K. Nguyen, N. N. M. Adnan, S. Oliver, S. Shanmugam and J. Yeow, Chem. Rev., 2016, 116, 1803-1949.

17. C. Boyer, A. Atme, C. Waldron, A. Anastasaki, P. Wilson, P. B. Zetterlund, D. Haddleton and M. R. Whittaker, Polym. Chem., 2013, 4, 106-112.

18. G. R. Jones, Z. Li, A. Anastasaki, D. J. Lloyd, P. Wilson, Q. Zhang and D. M. Haddleton, Macromolecules, 2016, 49, 483-489.

19. R. Whitfield, A. Anastasaki, N. P. Truong, P. Wilson, K. Kempe, J. A. Burns, T. P. Davis and D. M. Haddleton, Macromolecules, 2016, 49, 8914-8924.

20. A. Anastasaki, C. Waldron, P. Wilson, C. Boyer, P. B. Zetterlund, M. R. Whittaker and D. Haddleton, ACS Macro Lett., 2013, 2, 896-900.

21. C. Boyer, A. H. Soeriyadi, P. B. Zetterlund and M. R. Whittaker, Macromolecules, 2011, 44, 8028-8033.

22. C. Waldron, A. Anastasaki, R. McHale, P. Wilson, Z. Li, T. Smith and D. M. Haddleton, Polym. Chem., 2014, 5, 892-898.

23. M. R. Whittaker, C. N. Urbani and M. J. Monteiro, J. Polym. Sci., Part A: Polym. Chem., 2008, 46, 6346-6357.

24. C. Boyer, A. Derveaux, P. B. Zetterlund and M. R. Whittaker, Polym. Chem., 2012, 3, 117-123.

25. R. Aksakal, M. Resmini and C. R. Becer, Polym. Chem., 2016, 7, 171-175.

26. B. M. Rosen, G. Lligadas, C. Hahn and V. Percec, J. Polym. Sci., Part A: Polym. Chem., 2009, 47, 3940-3948.

27. B. D. Hornby, A. G. West, J. C. Tom, C. Waterson, S. Harrisson and S. Perrier, Macromol. Rapid Commun., 2010, 31, 1276-1280.

28. S. Fleischmann and V. Percec, J. Polym. Sci., Part A: Polym. Chem., 2010, 48, 2236-2242.

29. N. Risangud, T. R. Congdon, D. J. Keddie, P. Wilson, K. Kempe and D. M. Haddleton, J. Polym. Sci., Part A: Polym. Chem., 2016, 54, 2698-2705. 
30. A. J. D. Magenau, Y. Kwak and K. Matyjaszewski, Macromolecules, 2010, 43, 9682-9689.

31. R. Whitfield, A. Anastasaki, V. Nikolaou, G. R. Jones, N. G. Engelis, E. H. Discekici, C.

Fleischmann, J. Willenbacher, C. J. Hawker and D. M. Haddleton, J. Am. Chem. Soc., 2017, 139, 1003-1010.

32. M. Ciampolini and N. Nardi, Inorg. Chem., 1966, 5, 41-44.

33. N. H. Nguyen, B. M. Rosen and V. Percec, J. Polym. Sci., Part A: Polym. Chem., 2011, 49, 1235-1247.

34. G. Lligadas and V. Percec, J. Polym. Sci., Part A: Polym. Chem., 2008, 46, 6880-6895.

35. G. Lligadas, B. M. Rosen, M. J. Monteiro and V. Percec, Macromolecules, 2008, 41, 83608364.

36. N. H. Nguyen, M. E. Levere, J. Kulis, M. J. Monteiro and V. Percec, Macromolecules, 2012, 45, 4606-4622.

37. M. D. Zammit, M. L. Coote, T. P. Davis and G. D. Willett, Macromolecules, 1998, 31, 955-963.

38. N. H. Nguyen, X. Leng and V. Percec, Polym. Chem., 2013, 4, 2760-2766.

39. K. Matyjaszewski, J.-L. Wang, T. Grimaud and D. A. Shipp, Macromolecules, 1998, 31, 15271534.

40. A. Anastasaki, C. Waldron, P. Wilson, R. McHale and D. Haddleton, Polym. Chem., 2013.

41. A. H. Soeriyadi, C. Boyer, F. Nyström, P. B. Zetterlund and M. R. Whittaker, J. Am. Chem. Soc., 2011, 133, 11128-11131.

42. V. B. Sadhu, J. Pionteck, D. Voigt, H. Komber, D. Fischer and B. Voit, Macromol. Chem. Phys., 2004, 205, 2356-2365.

43. V. Darcos, S. Monge and D. M. Haddleton, J. Polym. Sci., Part A: Polym. Chem., 2004, 42, 4933-4940.

44. M. E. Levere, I. Willoughby, S. O'Donohue, A. de Cuendias, A. J. Grice, C. Fidge, C. R. Becer and D. M. Haddleton, Polym. Chem., 2010, 1, 1086-1094.

45. G. Lligadas and V. Percec, J. Polym. Sci., Part A: Polym. Chem., 2008, 46, 3174-3181.

46. S. R. Samanta, H.-J. Sun, A. Anastasaki, D. M. Haddleton and V. Percec, Polym. Chem., 2014, 5, 89-95.

47. H. Mayr, M. Roth and R. Faust, Macromolecules, 1996, 29, 6110-6113.

48. J. Morick, M. Buback and K. Matyjaszewski, Macromol. Chem. Phys., 2012, 213, 2287-2292.

49. M. Benaglia, A. Alberti, L. Giorgini, F. Magnoni and S. Tozzi, Polym. Chem., 2013, 4, 124-132. 